\title{
ТЕОРИЯ
}

\section{ОСНОВНЫЕ ТРЕНДЫ МИРОВОГО РАЗВИТИЯ: РЕАЛИИ И ПЕРСПЕКТИВЫ}

\author{
Чумаков А. Н.
}

\begin{abstract}
В статье анализируются ключевые параметры развития современного мира, его архитектоника и наиболее важные тенденции развития. Рассматриваются также современные коммуникации и принцииь взаимодействия различных общественных систем, составляющих в своей совокупности все мировое сообщество. В итоге вылеляются самые значимые культурноцивилизационные системь - Запад, Китай, Исламский мир и Россия, которые олицетворяют собою четыре основных глобальных тренда или четыре вектора силь, принципиально влияющих на современное состояние и перспективы мирового развития. При этом подчеркивается, что у Запада и Китая есть обеспеченная объективными обстоятельствами глобальная стратегия. У Исламского мира имеется глобальная стратегия, но возможности ее реализации ограничены объективными обстоятельствами. У России нет глобальной стратегии и отсутствуют объективные возможности для ее формирования. Вместе с тем региональное влияние и в целом планетарное значение России столь велики, что в условиях глобальной взаимозависимости она серьезно воздействует на международную обстановку, существенно корректируя ход мировых событий.
\end{abstract}

Ключевые слова: глобальный мир, мировое сообщество, развитие, взаимодействие, сила, диалог, культура.

The article analyzes the main parameters of the modern world development, its architectonics and the most important development trends. Modern communications and principles of various social systems' interaction are also considered. As a result, the most significant cultural-cum-civilizational systems are distinguishedthe West, China, the Islamic world and Russia, which represent four global trends or four vectors of power that fundamentally affect the current state and prospects of world development. At the same time, it is emphasized that the West and China have a global strategy provided by objective circumstances. The Islamic world has a global strategy, but the possibilities of its implementation are limited by objective circumstances. Russia does not have a global strategy and there are no objective opportunities to build it. At the same time, Russia's regional influence and global importance are so great that in the context of global interdependence it has a serious impact on the international situation, significantly adjusting the course of world events.

\footnotetext{
* Чумаков Александр Николаевич - д. ф. н., профессор МГУ имени М. В. Ломоносова, в. н. с. Института философии РАН, первый вице-президент Российского философского общества. E-mail: chumakov@iph.ras.ru.
} 
Keywords: global world, world community, development, interaction, power, dialogue, culture.

\section{Современные реалии глобального мира}

Под влиянием многоаспектной глобализации современный мир кардинально меняется, обнаруживая при этом все более явную тенденцию к обострению противоречий как на глобальном, так и на региональном, локальном (национальном) уровнях. Термин «глокализация», активно вошедший в научный оборот с начала нашего столетия, достаточно хорошо отражает суть данной ситуации, описывая взаимовлияние глобального и локального, единичного и общего, национального и общечеловеческого в процессе взаимодействия различных общественных систем [Global... 2014: 242]. На локальном и региональном уровнях это проявляется в росте сепаратизма, в стремлении национальных государств усилить свои позиции, в миграционном кризисе и провале политики мультикультурализма на просторах Европейского союза, в обострении ситуации на Корейском полуострове и т. п. В планетарном масштабе также усиливается нестабильность международных отношений, увеличивается напряжение, обостряются разногласия, ярким выражением чего является нарастающая политика санкций, перманентные торговые войны, расширение сфер применения «мягкой силы» или, например, ведение гибридной войны. Неменьшую обеспокоенность вызывает и постоянная угроза ядерного конфликта.

Все это не может не вызывать растущего беспокойства как на уровне широкого общественного сознания, так и в научных кругах [Chumakov, Gay 2016: 9-22]. При этом устоявшееся мнение о том, что человек за всю историю своего существования еще никогда не подвергался такой опасности, как теперь, соотносится обычно с такими явными и бесспорными глобальными проблемами, как угроза ядерной войны, экологический кризис, международный терроризм и т. п. И хотя это действительно так, суть проблемы только к этому не сводится. Дело заключается теперь уже не только в наличии ядерного оружия, которое и в самом деле плохо контролируется, грозя человечеству реальной возможностью самоуничтожения, и даже не во все возрастающем воздействии человека на окружающую среду или терроризме, вышедшем на глобальный уровень. Главная проблема заключается в самом человеке, как это было вполне очевидно уже В. И. Вернадскому, А. Печчеи или, например, Н. Н. Моисееву [Вернадский 1988; Моисеев 1998; Печчеи 1980; Global... 2017: 322-324, 255-257]. И эта опасность, которая сегодня многократно возрастает в силу стремительно развивающейся информационнотехнологической революции, сводится к тому, что ко всему комплексу глобальных проблем современности добавляется теперь новая угроза - кардинальное и быстрое изменение архитектоники мировых связей и отношений, тогда как мировое сообщество демонстрирует свою полную неспособность адекватно реагировать на эти перемены. Об этом же говорят и авторы серьезного исследования по истории технологий и их будущего, когда отмечают, что «научно-технический прогресс... в целом имеет тенденцию к ускорению. А вместе с ним ускоряется и исторический процесс, за которым ни индивидуальное, ни общественное сознание не может угнаться» [Гринин Л. Е., Гринин А. Л. 2015: 13].

Главными причинами такого положения дел являются, с одной стороны, предельная сложность проблем, требующих согласованных и адекватных решений на 
глобальном уровне, а с другой - двойственная, биосоциальная природа человека, который воплощает в себе не только хорошее, но и плохое: добро и зло, любовь и ненависть, миролюбие и агрессию и т. д. Конечно же, в историческом контексте, по мере цивилизационного развития, можно говорить об определенных позитивных переменах в поведении людей. Так, в частности, культура, воспитание, образование и просвещение делают человека более гуманным, терпимым, толерантным [Чумаков 2011; 2015]. Однако в нем сохраняется и то, что предопределено естественной, биологической природой, на уровне генетического кода. Именно здесь в значительной степени кроются его борьба за выживание, стремление к доминированию, агрессивность, решение проблем с позиции силы и т. п.

Тем же самым характеризуется и поведение отдельных сообществ - от небольших групп до национальных государств - и всевозможных их альянсов. Вот почему и сегодня мировое сообщество являет собой пеструю картину всевозможных общественных структур, находящихся на разных стадиях своего развития, когда сплошь и рядом соседствуют дикость, варварство и цивилизация [Урсул 2016]. К тому же они зачастую так переплетены, что трудно различить, где заканчивается одна и начинается другая стадия развития. А между тем и без того перенаселенная планета продолжает уплотняться за счет все возрастающего населения. И это притом что ресурсы Земли, необходимые для обеспечения жизнедеятельности людей, не только ограничены, но и распределены, как и население планеты, неравномерно. Отсюда явная и скрытая борьба, которая непрерывно идет за доступ к ресурсам, и нет оснований полагать, что в обозримой перспективе конфликт интересов ослабнет, а противоборство будет затухать.

Таким образом, вполне очевидно, что процессы глобализации принципиально повлияли на архитектонику мирового сообщества, сделав его полностью планетарным явлением, а отношения, связи, коммуникации и информационные потоки - трансграничными. Все это дает основание рассматривать теперь человечество в качестве единой, целостной системы относительно практически всех параметров общественной жизни. К тому же важно подчеркнуть, что национальные государства, которых насчитывается уже около 200, перестали быть единственными субъектами международных отношений, поскольку в таком же качестве выступают теперь и множество международных организаций, транснациональных корпораций, в том числе и криминальных, связанных с международной преступностью и терроризмом, наркоторговлей и т. П. При этом весь данный мир с множеством взаимодействующих и противоборствующих субъектов, как и прежде, в основном лишь стихийно саморегулируется и никак не управляется. Данное обстоятельство заслуживает особого внимания, поскольку, не имея адекватной системы управления, мировое сообщество перед лицом принципиально новых вызовов и задач все больше втягивается в ситуацию неопределенности и нарастания противоречий.

По сути, это главная опасность для человечества, поскольку многочисленные экономические, политические, социальные и иные проблемы, вырастая до глобальных масштабов, выходят из-под контроля национальных государств и не получают адекватного решения. Национальные же государства сегодня являются главными субъектами международных отношений. А поскольку каждое из них преследует в первую очередь собственные цели, то это приводит к столкновению их интересов, которые они отстаивают всеми доступными им средствами. В итоге 
многочисленные разногласия и конфликты на международной арене решаются в основном, как и прежде, с позиции силы. При этом сила не всегда используется непосредственно или выступает в грубой и неприкрытой форме. Зачастую, особенно в политике и экономике, принуждение происходит теперь посредством косвенного воздействия, именуемого «мягкой силой».

\section{Новые инструменты мировой политики}

Примеров эффективного использования «мягкой силы» множество - от всепроникающего влияния киноиндустрии Голливуда до проведения международных спортивных состязаний, обучения иностранных студентов или торговых систем типа «Макдоналдс». Весьма показательной в этом отношении является международная деятельность Китая в гуманитарной сфере, где активно используется культурная «мягкая сила» в отношениях с различными государствами. Так, учрежденный по китайской инициативе Всемирный культурный форум (Тайху) стал не только заметным явлением мировой культурной жизни, но и важным фактором влияния с позиции «мягкой силы» на общественное сознание во многих странах мира [Чумаков 2014; Ту Вэймин 2014].

Еще одним направлением использования культурной «мягкой силы» в современном мире является философия, которая, казалось бы, далека от реальной практики принятия конкретных решений. Но это не совсем так, что особенно хорошо видно опять-таки на примере Китая. Еще недавно он не придавал большого значения данной сфере общественной жизни, когда дело касалось международных отношений. Но за последние годы ситуация стала кардинально меняться. В частности, во Всемирных философских конгрессах, которые регулярно проводятся с 1900 г. через каждые пять лет, участие китайских философов до последнего времени было незначительным. Однако уже на XXII Всемирном философском конгрессе, который впервые за всю историю их проведения состоялся в Азии (в Сеуле) в 2008 г., китайская делегация была уже одной из самых представительных. И хотя в руководстве секций, круглых столов и симпозиумов на этом конгрессе китайских философов было еще совсем мало, а также их не было и среди пленарных докладчиков, влияние китайской философии на работу конгресса было уже хорошо заметным. Через пять лет, на XXIII Всемирном философском конгрессе, состоявшемся в 2013 г. в Афинах (Греция), ситуация еще больше изменилась. На этот раз китайская делегация по своей численности была уже на четвертом месте после Греции, России и США. При этом китайские философы были широко представлены в работе многих секций и круглых столов, где они очень активно выступали. Руководитель китайской делегации профессор Ту Вэймин руководил большой секцией «Confucian Philosophy», а также выступил с докладом на Генеральной ассамблее Международной федерации философских обществ и стал одной из наиболее значимых фигур на конгрессе. Все это существенно повлияло на то, что следующий XXIV Всемирный философский конгресс по решению Генеральной Ассамблеи Всемирной федерации философских обществ состоялся в августе 2018 г. в Пекине. Несомненно, это большой успех современной китайской философии, который является хорошим примером использования культурной «мягкой силы» на международном уровне в гуманитарной сфере.

Значительные надежды на решение международных проблем, как и прежде, возлагаются на Организацию Объединенных Наций и ее многочисленные струк- 
туры. Однако с тех пор, как была создана эта организация, кардинально изменились и время, и обстоятельства. Сегодня ООН оказывается практически бессильной перед лицом современных вызовов, поскольку создавалась она в иное время и для решения других задач - прежде всего для погашения военных конфликтов и предотвращения новой мировой войны посредством исполнения регулятивных функций на мировой арене. Теперь же обстоятельства настоятельно требуют управления глобальным миром, но возможности практической реализации такой задачи остаются туманными, поскольку данная проблема не получила пока еще даже теоретического решения. Иными словами, вопрос о принципиальной возможности управления мировой общественной системой остается открытым. Отсюда нет оснований полагать, что реформа ООН сама по себе может что-то кардинально изменить в этом отношении, хотя определенные попытки реагировать на актуальные вызовы современности так или иначе периодически предпринимаются.

В итоге появляются все новые глобальные и региональные наднациональные структуры, такие, например, как Европейский союз, ВТО, Всемирный банк, Шанхайская организация сотрудничества, «Большая семерка», «Большая двадцатка» и др. Однако следует иметь в виду, что все эти и подобные им организации создаются для обеспечения согласованных действий на глобальном или региональных уровнях. И следует признать, что с такого рода задачами они в той или иной мере справляются. Вместе с тем основное противоречие современной эпохи, как было сказано выше, такие организации не могут решить в принципе, поскольку их реальные возможности несоизмеримо меньше тех, которые требуются на глобальном уровне применительно ко всему человечеству, да еще и в различных сферах общественной жизни. И в самом деле, все они имеют отношение только к отдельным сферам человеческой деятельности, да к тому же, как правило, охватывают лишь часть человечества или какой-то регион. При этом все они достаточно автономны и не представляют мир в целом, во всех его ипостасях, без чего ни о каком глобальном управлении не может быть и речи. В мировом масштабе такие организации способны выполнить в лучшем случае некоторые функции регулирования, но не предназначены для управления мировой системой как единым целым и потому не имеют возможностей для этого.

Именно этим можно объяснить то, что практически все глобальные проекты последнего времени, среди которых наибольшую известность получили «политика мирного сосуществования», «концепция устойчивого развития», идея «ноосферы», «политика мультикультурализма» и т. п., не приводят к желаемым результатам и чаще всего оказываются несостоятельными, поскольку не обеспечены соответствующими механизмами реализации такого рода идей. Отсюда можно заключить, что конфликт интересов в глобальном мире и далее будет усиливаться, а все большая открытость и доступность информации, которая стала сегодня важнейшим ресурсом и эффективным инструментом управления общественными процессами, будут этому способствовать.

\section{Архитектоника и коммуникации планетарного сообщества}

То, что устройство современного мира непосредственно предопределено его содержанием, представляется очевидным. Именно характер и структура мирового порядка, а также реальный расклад сил в мировом сообществе в значительной 
мере предопределяют итоги столкновения бесчисленного количества интересов, которые на глобальном уровне пытаются реализовать различные субъекты международных отношений. При этом принципиальное значение обретает вопрос о современном и будущем устройстве нашего мира, который при всех несовершенствах и противоречиях, присущих не только ему, но и самому человеку, мог бы гарантировать будущему мировому сообществу и всей планете в целом если не благополучное, то хотя бы как минимум приемлемое существование. В этой связи следует подчеркнуть, что человеку нет надобности создавать рай на Земле, поскольку все, что обычно ассоциируется с раем, уже существует, причем именно здесь, на нашей планете. И создано все это по большей части без преобразующей деятельности человека. Иными словами, на Земле есть абсолютно все, в чем люди нуждаются для их полноценной, счастливой и полной радости жизни. А вот если этот мир становится для людей некомфортным или непригодным для жизни, а то и вовсе адом, это уже проблема по большей части не природного свойства, а самого человека. Потому вполне можно согласиться с М. С. Горбачевым, когда он формулирует положение принципиальной важности: «Как научиться жить самим, давая жить “по-своему" другим - такова основная идея и проблема глобализации» [Горбачев 2005: 9].

В этой связи можно и нужно уповать на диалог, который в современных условиях нередко перемежается с «мягкой силой», а то и с применением санкций, которые, в отличие от горячих конфликтов, оставляют место диалогу. Несомненно, санкции - это плохо, поскольку они наносят вред не только той стороне, против которой направлены, но и стороне, использующей такие меры воздействия. Однако нельзя не признать и того, что в условиях жесткого противостояния и острой борьбы на международной арене, где отсутствует эффективное правовое регулирование, а главным арбитром выступает военная сила, санкции оказываются все-таки меньшим злом, чем военное решение проблем. Иными словами, в такой ситуации они, конечно же, создают серьезное напряжение, но в то же время и удерживают общественные отношения в рамках относительно умеренной конфронтации и цивилизационного развития.

При этом важно подчеркнуть, что диалог, а тем более санкции, сами по себе проблем не решают, поскольку выступают лишь средством, инструментом, формой взаимодействия на пути к их разрешению. Главный же результат, на который можно рассчитывать в итоге диалога, в значительной степени предопределяется условиями, в которых он протекает. Примером, подтверждающим сказанное, может служить глобальное противостояние в XX в. двух общественно-политических систем - капитализма и социализма. Непримиримая борьба этих двух основных антагонистических по своей природе полюсов разнонаправленных сил в основном и предопределяла ход мировых событий прошлого века. Страны третьего мира, часть из которых именовали себя «неприсоединившимися», были в массе своей аморфным и не скрепленным какой-либо общей идеологией конгломератом, что делало их в известной степени объектом влияния и манипулирования со стороны двух упомянутых выше блоков. Таким образом, в биполярном мире диалог между противоборствующими сторонами хотя и был сильно идеологизированным и предельно заостренным, тем не менее играл исключительно важную роль в деле сохранения мира и недопущения ядерной войны. В итоге следует при- 
знать, что в тех условиях это было пределом возможностей мирного решения противоречий.

Заметим также, что относительно мирное завершение того этапа холодной войны стало результатом в том числе и напряженного диалога, который не прекращался фактически все время противостояния двух систем, то есть двух полюсов антагонистических идеологий и военной конфронтации. Распад социалистической системы кардинально изменил соотношение сил на международной арене. Не последнюю роль в этом сыграла также глобализация, в результате чего прежний порядок вещей на планете уступил место новому, когда глобальный мир «переполюсовался» и стал на определенное время фактически однополярным. Во всяком случае, так это виделось многим на Западе, что наиболее ярко выразили в 1990-е гг. в своих работах такие известные политологи, как Ф. Фукуяма, З. Бжезинский, Ч. Краутхаммер, Дж. Чейз и др. Так, например, Фукуяма в получившей широкую известность статье «Конец истории» писал: «Триумф Запада, западной идеи очевиден прежде всего потому, что у либерализма не осталось никаких жизнеспособных альтернатив... То, чему мы, вероятно, свидетели, не просто конец холодной войны или очередного периода послевоенной истории, но конец истории как таковой, завершение идеологической эволюции человечества и универсализации западной либеральной демократии как окончательной формы правления» [Фукуяма 1990: 134].

При этом особая и первостепенная роль в исторической миссии Запада безоговорочно отводилась США. В изложении российского политолога А. С. Панарина такое положение дел поясняется следующим образом: «Именно: чтобы оставаться внутри себя демократически открытым и процветающим обществом, подтверждающим ожидания морали успеха, США неизбежно предстоит превратиться в завоевательное империалистическое общество, готовое прибрать к рукам ресурсы остального мира, а сопротивление последнего подавить силой... Именно поэтому окончание холодной войны, вместо того чтобы стать основанием демилитаризации Америки и отказа от силовых методов в политике, стало отправной точкой глобального проекта овладения миром» [Панарин 2000: 106]. И в самом деле, практически не имевший в то время противовеса западный мир, в частности Соединенные Штаты, стал восприниматься как единственный полюс и безальтернативный центр силы, только и способный поддерживать мировой порядок. Такая позиция достаточно четко была выражена Ч. Краутхаммером, который на завершающем этапе распада СССР заявил, что «в грядущие поколения, возможно, и появятся великие державы, равные Соединенным Штатам. Но им это не удастся. Не в эти десятилетия. Мы переживаем момент однополярности» [Krauthammer 1991: 23-24].

Подобное настроение и аналогичное мнение о роли и историческом предназначении США в мировых делах шестью годами позже выразил также известный американский политолог 3. Бжезинский. Он еще более четко сформулировал суть данной позиции, когда писал: «Америка стоит в центре взаимозависимой вселенной, такой, в которой власть осуществляется через постоянное маневрирование, диалог, диффузию и стремление к формальному консенсусу, хотя эта власть происходит в конце концов из единого источника, а именно: Вашингтон, округ Колумбия. И именно здесь должны вестись политические игры в сфере власти, причем по внутренним правилам Америки» [Бжезинский 1998: 40-41]. Вместе с тем 
следует подчеркнуть, что уже в данной книге автор предпринимает попытку критического осмысления перспектив сохранения лидирующих позиций США, предполагая, что представление об однополярном мире в перспективе вряд ли будет соответствовать реальному положению дел. Так, в частности, говоря о всеобъемлющей и скоординированной геостратегии в отношении Евразии, З. Бжезинский отмечает, что такая стратегия «должна опираться на признание границ эффективного влияния Америки и неизбежное сужение с течением времени рамок этого влияния... И поскольку беспрецедентное влияние Америки с течением времени будет уменьшаться, приоритет должен быть отдан контролю за процессом усиления других региональных держав, с тем, чтобы он шел в направлении, не угрожающем главенствующей роли Америки в мире» [Бжезинский 1998: 234].

Тогда же, во второй половине 1990-х гг., стали высказываться еще более критические взгляды на однополярное устройство мира; причем не только на постсоветском пространстве, но и на Западе. Так, в частности, С. Хантингтон в своей известной работе «Столкновение цивилизаций» писал буквально следующее: «Политика в мире после "холодной войны" впервые в истории стала и многополюсной, и полицивилизационной» [Хантингтон 2003: 16]. Не менее четко свою позицию сформулировал и постоянный представитель Японии в ООН Х. Овада, который и вовсе заявил, что «однополярный мир является опасным заблуждением; на самом деле порядок в мире не может диктоваться волей лишь одного полюса, каким бы могущественным ни был этот полюс в сравнительном плане» [Owada 1998: 56].

Суммируя, можно сказать, что к концу XX в., когда в основном закончилось переформатирование мирового порядка, позиции Запада явно усилились. В то же время негативные последствия войны в Ираке, массированная террористическая атака на США 11 сентября 2001 г. и все более четкое оформление межгосударственных отношений на постсоветском пространстве, равно как и усиление роли и влияния на международной арене ряда развивающихся странах, в особенности в Юго-Восточной Азии, существенно ослабили позиции сторонников концепции однополярного мира. Становилось все более очевидным, что такие взгляды не соответствуют реальному положению дел на мировой арене. И также все больше приходило осознание того, что не только США, но и западный мир в целом не способны выполнять роль мирового жандарма или хотя бы арбитра в мире, где окончательно установились глобальные связи и отношения. И тот факт, что у стран Запада больше возможностей по сравнению с другими странами или их объединениями влиять на мировую политику, вовсе не означает, что у них есть реальные возможности и в самом деле быть полноправными хозяевами положения дел на мировой арене. Отсюда, поскольку решающего голоса, или, образно выражаясь, «контрольного пакета акций», сегодня нет явно ни у кого и каждый субъект международных отношений играет свою роль в зависимости от его места и положения в мировом сообществе, то и разговоры об однополярном мире потеряли свою актуальность. Сказанное вовсе не означает, что по отдельным параметрам общественной жизни, например, по военному потенциалу или по валовому национальному продукту, у той или иной страны не может быть явного приоритета над другими; однако по совокупности всех явных и неявных, духовных и материальных, реальных и потенциальных возможностей абсолютным, а тем более 
стабильным и долговременным преимуществом не обладает ни одна страна или какой бы то ни было их альянс.

В итоге мы наблюдаем ситуацию, когда глобальный мир не имеет единого во всех отношениях центра принятия решений. В этой связи можно было бы провести аналогию со словами Н. Кузанского, который еще в XV в., рассуждая о бесконечности мироздания, утверждал, что в нем нет раз и навсегда установленного центра и правильно было бы говорить, что он «везде и нигде» [Кузанский 1979: 134]. По существу именно так обстоит дело и теперь в глобально взаимозависимом мире. В нем есть определенный перевес одних сил над другими, но нет постоянства в раскладе этих сил, если иметь в виду различные субъекты международных отношений. В действительности одни из этих субъектов усиливаются, другие ослабевают, в том числе и за счет обретения или потери союзников, объединения, кооперации или, напротив, расставания с кем-то. В таких условиях можно как обрести, так и потерять поддержку и расположение к себе, а можно и просто занять выжидательную позицию в готовности примкнуть к более сильной стороне в тот или иной выгодный для себя момент. Именно так и поступают, как правило, взаимодействующие субъекты, руководствуясь собственными интересами и своим реальным положением в системе международных отношений. В конечном же счете итогом сложения всех этих разнонаправленных векторов поведения становится то, что центров влияния и принятия решений в глобально устроенном мире оказывается много. При этом реальный расклад в отношениях между ними постоянно меняется, варьируя от тесной кооперации до жесткого противостояния. И нередко реальный центр принятия решений оказывается не там, где он декларируется или подразумевается, а совсем в другом месте, к тому же и не слишком афишируемом. Можно сказать в итоге, что мы вступили в эпоху особого мироустройства и таких отношений, которые характеризуются полицентризмом, многополярностью и многократно возросшей мобильностью.

\section{Основные тренды мирового развития}

Итак, приходим к тому, что при все нарастающей глобальной взаимозависимости человечество не только не преодолело прежней раздробленности, но еще больше впуталось в клубок противоречий, представляя собою пеструю картину разнонаправленных сил. При этом абсолютное большинство субъектов международных отношений занято решением в основном тактических задач локального и регионального масштаба. Иметь же амбиции глобального уровня, тем более выстраивать стратегические планы, располагая реальными возможностями для их реализации, могут позволить себе лишь единицы. Как следствие, жесткая борьба за лидерство на этом уровне ведется с использованием всех возможностей и ресурсов между четырьмя основными центрами влияния. Иными словами, речь идет о четырех культурно-цивилизационных системах, представляющих собою четыре вектора силь мирового масштаба, или четыре основных глобальных тренда, которые уже сегодня в наибольшей степени воздействуют на развитие мировых процессов и реально имеют серьезные возможности кардинально повлиять на облик глобального человечества и планетарной конструкции в целом.

В приоритетном порядке такие культурно-циивилизационные системы, место, роль и значение которых в мировых делах, бесспорно, имеют глобальное измере- 
ние, следует расположить следующим образом: страны Запада, или обобщенно Западный мир; Китай; Исламский мир и Россия.

При этом как Запад, так и Китай имеют амбиции, соответствующие идеологии и потенциальные возможности стать мировым гегемоном, к чему они, несомненно, стремятся. Разница лишь в том, что если высокотехнологичный, «разветвленный», но по политико-экономическим и цивилизационным основаниям в общем-то единый Запад заявляет об этом явно и словом, и делом, то перенаселенный и уверенно наращивающий свой экономический потенциал Китай стремится выстраивать свои глобальные стратегии, явно не афишируя их.

Исламский мир, при всем его разнообразии и разноплановости, также имеет соответствующую идеологию и амбиции планетарного масштаба. Достаточно сослаться на его стремление к максимальной исламизации планеты. Однако его глобальная стратегия ограничена объективными обстоятельствами, лишающими ислам возможности для реализации данной идеи. Помимо серьезных разногласий и противоречий внутри самого ислама, эта религиозная система практически не имеет возможности для своего экстенсивного распространения в мировом сообществе уже хотя бы по той причине, что необходимые для этого свободные конфессиональные ниши на планете отсутствуют. А поскольку у ислама в принципе нет перспектив решения такой задачи, то это толкает его наиболее радикальные течения на путь террора и насилия. В этом можно усмотреть их стремление найти применение своей нереализованной пассионарности. Схожее объяснение корней терроризма, но с несколько иных позиций, дает В. Г. Федотова, которая, в частности, пишет: «Приняв западный консьюмеризм, исламский мир не принял его социальных и культурных ценностей... такая позиция мусульман-террористов, получивших все от Америки, возникла из-за того, что они увидели, что у их народов нет шансов» [Федотова 2005: 303].

Что касается России, то в силу сложившихся в постсоветский период объективных обстоятельств у нее, в отличие от СССР, нет ни глобальных амбиций, ни соответствующей идеологии, а потому нет и глобальной стратегии, целенаправленно ориентированной на изменение или хотя бы какое-то преобразование всего мира. Вместе с тем геополитическое положение, военно-промышленный потенциал, ядерный комплекс и космические программы, а также региональное влияние и роль России на постсоветском пространстве столь велики, что в условиях глобальной взаимозависимости ее внешнеполитическая деятельность является весьма серьезным фактором воздействия на ход мировых событий.

Характеризуя названные выше четыре культурно-цивилизационные системы, представляющие собою четыре разнонаправленных вектора в системе мирового развития, отметим также и то, что ни один из этих векторов не может быть кардинально изменен в результате внешнего, тем более исключительно силового воздействия. А это означает, что как минимум на обозримую перспективу противостояние и борьба в первую очередь между этими четырьмя центрами силы продолжатся, и нет причин рассчитывать на их ослабление [Ильин, Урсул 2016]. И хотя множество других, менее значительных центров сил и принятия решений могут быть тем или иным путем принуждены к определенной линии поведения, в целом это глобальному миру стабильности не добавит.

Таким образом, если задаться вопросом, возможна ли принципиальная, снимающая антагонистические противоречия интеграция с Западом, и если возмож- 
на, то как, на какой основе, ответ будет однозначным - такое может произойти не иначе как на платформе данной культурно-цивилизационной системы. Иными словами, лишь только на условиях Запада, поскольку он не может отказаться от своих принципов и ценностей, не утратив при этом своей идентичности.

Точно так же и в вопросе об интеграции с Китаем. Ни о какой иной интеграции с ним, кроме как на его платформе и на его условиях, не может быть и речи. Китайцы тысячелетиями воспроизводят свою оригинальную культуру, ценности и традиции, которые, разве что с некоторыми вариациями, будут воспроизводиться столько, сколько будет существовать Китай.

Аналогичный ответ на сформулированный выше вопрос будет и касательно Исламского мира, поскольку его ценности, нормы морали и образ жизни, жестко детерминированные Кораном, лишь предлагаются другим в изначальном и неизменном виде, тогда как собственные трансформации, тем более под влиянием внешних обстоятельств, абсолютно исключены.

Наконец, таким же вопросом зададимся и относительно России. Кто и как мог бы основательно, на прочной и долговременной основе интегрироваться с нею? Оставляя открытым вопрос касательно ближайших соседей нашей страны, можно констатировать, что после утраты обращенной ко всему миру коммунистической идеологии у нее теперь нет такой концепции, которую она могла бы предложить всему человечеству в качестве перспективной модели исторического развития. И более того, прежде чем предложить остальным народам мира привлекательную и приемлемую основу для всеобщего объединения, России необходимо еще как минимум сформулировать собственную стратегию развития, задающую вектор поступательного движения в будущее.

С учетом сказанного можно заключить, что диапазон возможных сценариев развития для современного мира в целом находится в пределах между плохим и худшим. Отсюда весьма разнородные и постоянно противоборствующие всевозможные общественные системы, образующие мировое сообщество, могут рассчитывать на согласованность действий лишь в отдельных случаях, приходя к этому путем многочисленных переговоров, согласований, сопоставления своих позиций, интересов и т. п. При этом метод проб и ошибок не только не исключается, но и продолжает оставаться нормой. Также в обозримой перспективе не видно конца внутриполитическим и международным конфликтам, усилению торговых, информационных, кибернетических войн, с тем лишь уточнением, что революционные преобразования культурно-цивилизационных систем не только нежелательны, но и крайне опасны для международной стабильности [Махаматов 2017: 60]. К тому же при сложившемся раскладе сил и появлении все более совершенных средств и технологий манипулирования общественным сознанием наступление такого рода событий становится все менее вероятным. Также и в духовной сфере, где остро стоит вопрос о формировании нового гуманизма и пересмотре существующей системы ценностей, изменения, скорее всего, будут происходить хотя и с ускорением, но преимущественно эволюционным путем.

Конечно, экономические интересы и политические разногласия, равно как и культурные особенности разных народов, всегда будут лежать в основе противоречий, порою острейших, и здесь не должно быть иллюзий. Но отсутствие общих целей и подходов для их достижения, равно как и принципов, ценностных установок и приемлемого языка общения всегда будет непреодолимым препятствием 
на пути если не полного единения, то хотя бы взаимопонимания стран и народов в условиях, когда от этого никто не может уклониться. Таким образом, мировое сообщество стоит сегодня перед необходимостью серьезных, и прежде всего мировоззренческих, ценностных, духовных, перемен. Как никогда прежде оно нуждается теперь в глобальной цивилизационной революции, которая стала бы мощным импульсом формирования глобального гражданского общества, а в международных отношениях запустила бы процесс перехода от права силы к силе права. Пожалуй, это наиболее приемлемый путь дальнейшего развития, чтобы человечество могло рассчитывать на стабильную международную безопасность и построение нового мирового порядка, отвечающего современным реалиям и перспективам мирного сосуществования и устойчивого развития.

\section{Литература}

Бжезинский 3. Великая шахматная доска. Господство Америки и его геостратегические императивы. М. : Международные отношения, 1998.

Вернадский В. И. Философские мысли натуралиста. М. : Наука, 1988.

Горбачев М. С. Нет проблемы важнее и задачи труднее, чем эта // Диалог цивилизаций. Повестка дня. М. : ИФ РАН, 2005.

Гринин Л. Е., Гринин А. Л. От рубил до нанороботов. Мир на пути к эпохе самоуправляемых систем (история технологий и описание их будущего). М. : Учитель, 2015.

Ильин И. В., Урсул А. Д. Образование, общество, природа: эволюционный подход и глобальные перспективы // Вестник Московского университета. Серия 27. Глобалистика и геополитика. 2016. № 1. С. 93-94.

Кузанский Н. Соч.: в 2 т. Т. 1. М. : Мысль, 1979.

Махаматов Т. М. От эпохи глобализации к неоглобализации: культурноцивилизационный аспект // Век глобализации. 2017. № 4(24). С. 55-61.

Моисеев Н. Н. Судьба цивилизации. Путь разума. М. : МНЭПУ, 1998.

Панарин А. С. Искушение глобализмом. М. : Русский Национальный Фонд, 2000.

Печчеи А. Человеческие качества. М. : Прогресс, 1980.

Ту Вэймин. Разные взгляды на современность: о сущности Восточно-Азиатской модели современности // Век глобализации. 2014. №1(13). С. 3-12.

Урсул А. Д. Становление устойчивой цивилизации: новые глобальные цели // Философия и общество. 2016. №1(78). С. 29-56.

Федотова В. Г. Хорошее общество. М. : Прогресс-Традиция, 2005.

Фукуяма Ф. Конец истории? // Вопросы философии. 1990. № 3. С. 134-148.

Хантингтон С. Столкновение цивилизаций. М. : АСТ, 2003.

Чумаков А. Н. Культура в условиях глобальных трансформаций // Вестник Московского университета. Серия 27. Глобалистика и геополитика. 2011. № 1-2. C. $105-121$.

Чумаков А. Н. «Мягкая сила» как способ решения проблем в глобальном мире // Век глобализации. 2014. № 2(14). С. 192-195. 
Чумаков А. Н. Массовая культура как порождение и спутник глобализации // Вестник Московского университета. Серия 27. Глобалистика и геополитика. 2015. № 1-2. C. 120-131.

Chumakov A. N., Gay W. C. (eds.) Between Past Orthodoxies and the Future of Globalization: Contemporary Philosophical Problems. Leiden, Boston : Brill-Rodopi, 2016.

Global Studies Directory: People, Organization, Publications / Ed. by A. N. Chumakov, I. I. Ilyin, I. I. Mazour. Leiden; Boston : Brill, 2017.

Global Studies Encyclopedic Dictionary / Ed. by A. N. Chumakov, I. I. Mazour, W. C. Gay. Amsterdam; New York, NY, 2014.

Krauthammer Ch. The Unipolar Moment // Foreign Affairs. 1991. Summer. Pp. 23-33.

Owada H. The Problem of World Public Order // B. Boutros-Ghali Amicorum Discipulorumque Liber. Vol. I. Bruxelles, 1998. 